\title{
Erratum to: Rethinking National Competitiveness: A Critical Assessment of Governmental Capacity Measures
}

Tobin Im $^{1} \cdot$ Youngmi Choi ${ }^{2}$

Published online: 30 March 2017

(C) Springer Science+Business Media Dordrecht 2017

\section{Erratum to: Soc Indic Res \\ DOI 10.1007/s11205-016-1494-z}

In the original publication of this article, the acknowledgement section has been missed to publish. Now the acknowledgement has been provided in this erratum.

Acknowledgements This work was supported by National Research Foundation of Korea Grant funded by the Korean Government (NRF-2014S1A3A2044898).

The online version of the original article can be found under doi:10.1007/s11205-016-1494-z.

Youngmi Choi

ymchoi@jnu.ac.kr

Tobin Im

tobin@snu.ac.kr

1 Seoul National University, 1 Gwanak-ro, Kwanak-Gu, Seoul 08826, South Korea

2 Chonnam National University, 77 Yongbong-ro, Buk-gu, Gwangju 61186, South Korea 